\title{
Lipoprotein (a), an independent cardiovascular risk marker
}

\author{
Ramesh Saeedi ${ }^{1,2}$ and Jiri Frohlich ${ }^{1,2^{*}}$
}

\begin{abstract}
Epidemiological and genetic studies have identified elevated levels of lipoprotein (a) ((Lp(a)) as a causal and independent risk factor for cardiovascular diseases (CVD). The Lp(a)-induced increased risk of CVD may be mediated by both its proatherogenic and prothrombotic mechanisms. Several guidelines recommend screening of $L p(a)$ level; however, there are few treatment options for the management of patients with elevated Lp(a). Several new medications for Lp(a) are under development. PCSK9 inhibitors, apolipoprotein (a)-antisense, and apolipoprotein(B-100)-antisense mipomersen have shown promising results. Lp(a) reduction will continue to be an active area of investigation.
\end{abstract}

Keywords: Lipoprotein(a) [Lp(a)], Coronary artery disease (CAD), Niacin, Statins

\section{Background}

Most clinical trials research investigating the effects of cholesterol lowering medications on the prevention of cardiovascular disease (CVD) have focused on low density lipoprotein cholesterol (LDL-C). Elevated serum level of lipoprotein (a) $(\mathrm{Lp}(\mathrm{a}))$, an LDL particle linked to the plasminogen-like glycoprotein, has been an independent risk factor for atherosclerotic CVD, particularly in those with high low-density lipoprotein cholesterol (LDL-C) or non- high-density lipoprotein cholesterol (HDL-C) $[1,2]$. Effects of $L p(a)$ on vasculature are not fully understood. Human and animal studies have shown that $L$ (a) can enter intima of arteries [3]. Thus, it may have a role in inflammation of intima, thrombosis, and foam cell formation; all these processes are involved in development of atherosclerosis $[4,5]$. It is estimated that around 1.5 billion people have $\mathrm{Lp}$ (a) levels greater than $500 \mathrm{mg} / \mathrm{L}$ [6]. Lp(a) levels are, to a large extent genetically determined, stable are not significantly influenced by diet, exercise, or other environmental factors [6].

This review article addresses the structure, genetics, and function of $\mathrm{Lp}(\mathrm{a})$ as well as indications for screening and therapy.

\footnotetext{
* Correspondence: jifr@mail.ubc.ca

${ }^{1}$ Healthy Heart Program, St. Paul's Hospital, Rm 180-1081 Burrard Street, Vancouver, B.C V6Z 1Y6, Canada

${ }^{2}$ Pathology and Laboratory Medicine Department, University of British

Columbia, St. Paul's Hospital, Rm 180-1081 Burrard Street, Vancouver, B.C V6Z 1Y6, Canada
}

C 2016 Saeedi and Frohlich. Open Access This article is distributed under the terms of the Creative Commons Attribution 4.0 International License (http://creativecommons.org/licenses/by/4.0/), which permits unrestricted use, distribution, and reproduction in any medium, provided you give appropriate credit to the original author(s) and the source, provide a link to the Creative Commons license, and indicate if changes were made. The Creative Commons Public Domain Dedication waiver (http://creativecommons.org/publicdomain/zero/1.0/) applies to the data made available in this article, unless otherwise stated.
Lp(a) structure

The $\operatorname{Lp}(\mathrm{a})$ structure is similar to that of LDL, in which a glycoprotein, apolipoprotein(a) [apo(a)], is covalently bound to apolipoprotein B (apoB) by a disulfide bridge, in a 1:1 molar ratio [2]. Cholesterol content of $\mathrm{Lp}(\mathrm{a})$ as well as its density are similar to those of LDL particles. Its structure is similar to plasminogen, including a common gene sequence [2]. The apo(a) chain contains five domains or kringles; the fourth kringle has a homology with the fibrin-binding domain of plasminogen which causes $\mathrm{Lp}(\mathrm{a})$ interference with fibrinolysis. In addition, $\mathrm{Lp}$ (a) promotes foam cell formation and cholesterol deposition in atherosclerotic plaques by binding to macrophages [7].

\section{Lp(a) genetics and serum concentration}

Serum levels of $\mathrm{Lp}(\mathrm{a})$ are mostly genetically determined. The polymorphism in apo(a) gene [LPA] results in the heterogeneity in its size and molecular weight $[1,2]$. Lp(a) show high ethnic variability. Atherosclerosis Risk in Communities (ARIC) study has shown that median $\mathrm{Lp}(\mathrm{a})$ levels are three times higher in African-Americansas compared to the Caucasions [8]. Matthews et al. [9] also reported higher levels of $\mathrm{LP}(\mathrm{a})$ in African-American compared to Caucasians.

Distribution of Lp(a) concentrations is highly skewed particularly toward extremely high levels $[2,7,10]$. Lp(a) levels 
range between 20 to more than $2000 \mathrm{mg} / \mathrm{L}$ with almost $20 \%$ of individuals at the extreme levels $[2,7,10]$.

There is a heterogeneity in size of $\operatorname{Lp}(\mathrm{a})$, ranging from 187 to $662 \mathrm{KDa}$, it depends on the number of Kringle of IV type 2 repeats in the $L p(a)$ gene [11]. There is a strong inverse relationship between the size of $\mathrm{LP}(\mathrm{a})$ and its serum levels with smaller size correlating with higher serum levels [2]. Also smaller Lp(a) is associated with increased risks of cardiovascular disease (CVD). Due to its strong genetic determination, $\mathrm{Lp}(\mathrm{a})$ levels are stable and are not significantly influenced by gender, age, or environmental factors $[7,10]$.

\section{Lp(a) measurement}

Originally Lp(a) was detected by gel electrophoresis as a "sinking pre-beta lipoprotein" band [2]. There are issues regarding $\mathrm{Lp}(\mathrm{a})$ measurement and standardization which have complicated $\mathrm{Lp}(\mathrm{a})$ level interpretations in the context of CVD risk. There are several diferent methods of reporting $L p(a)$ leves that may confuse physicians. Some laboratories report $\mathrm{Lp}(\mathrm{a})$ mass, while others report it as $\mathrm{Lp}(\mathrm{a})$ concentration, or $\mathrm{Lp}(\mathrm{a})$ protein. Efforts has been made in standardization on measurement and reporting the $\mathrm{Lp}(\mathrm{a})$ levels. Several assays for measurement of $\mathrm{Lp}(\mathrm{a})$ are available, such as enzyme-linked immunosorbent assays (ELISAs), non-competitive ELISA, immunonephelometry, immunoturbidometry, and latex immunoassays [11-13]. The European Atherosclerosis Society guidelines [12] recommended use of method which is robust, accurate, economically priced with coefficient of variations $(\mathrm{CV})<10 \%$. Also they have recommended that antibodies which are used in assay kits should be apo(a) isoform-insensitive in which $\mathrm{Lp}(\mathrm{a})$ is measured independently of $\mathrm{Lp}(\mathrm{a})$ size and number of kringle-IV repeats. Immunoassays, protocols for blood collection, plasma/serum isolation should be standardized for quality control. A secondary reference $\operatorname{Lp}(\mathrm{a})$ preparation at an international level approved organizations such as International Federation of Clinical Chemistry and the World Health Organization. Manufactures making assays for measurement of $\mathrm{Lp}(\mathrm{a})$ should seek to minimize the effects of apo(a) size on Lp(a) levels and use isoforminsensitive polyclonal antibodies (anti-apo(a) capture and anti-apo(B) [11-15].

Denka-Seiken immunoturbidimetric assay (Atherotech Diagnostics Lab; Berkeley Extended-Range Lp(a) Test) is a high-duality and validated assay that measures $L p(a)$ mass with $\mathrm{CV}<3 \%$.

\section{Lp(a) and cardiovascular disease (CVD)}

Serum levels of $L p(a)$ are an independent risk factors for CVD. Several studies have indicated that the risk is markedly elevated at the extreme $\operatorname{Lp}(\mathrm{a})$ levels $[16,17]$. For example, the Copenhagen Heart Study showed that patients with $\mathrm{Lp}(\mathrm{a})$ levels above $500 \mathrm{mg} / \mathrm{L}$ have $2-3$ fold increase in the risk of myocardial infarction. A large Mendelian randomized study as well as the EPICNorfolk, and Brunek cohort studies demonstrated that patients with high Lp(a) levels have two-fold increase in CVD [7]. Recently Willeit et al. suggested that $L p(a)$ measurement, particularly in intermediate risk category of patient (as determined by Framingham risk score) predicts CVD outcomes and improves CVD risk prediction [18].

HIgh levels of Lp(a) are commonly detected in patients with premature coronary heart disease (CHD). Genest have reported elevated Lp(a) levels in $18.6 \%$ of patients with premature CHD with $12.7 \%$ of them having no dyslipidemia [19]. The National Cholesterol Education Program for the Detection, Evaluation and treatment of hypercholesteremia in adult (NCEP-ATP III) states that $\mathrm{Lp}(\mathrm{a})$ levels are predictor of CV risks with higher levels associated with greater risk of having an CV events [20]. The Emerging Risk Factors Collaboration have found that each 3.5-fold increase in $L p(a)$ resulted in a $13 \%$ increase in CVD risk [21]. They also found that this association was continuous and become proportionally more important with higher $\operatorname{Lp}(\mathrm{a})$ levels. Moreover, they found that this association still persist even after correction for other lipid parameters.

Size of Lp(a) also modulates CHD risk with the smaller apo(a) isoforms associated more strongly with the risk of CHD compared to larger isoforms [21]. Genome-wide association studies (GWAS), Mendelian randomization, and epidemiologic studies revealed a link between LPA genotype with high $\mathrm{Lp}(\mathrm{a})$ levels and adverse $\mathrm{CV}$ events [6]. In a systemic review of 40 studies involving 58,000 participants, Erqou et al. have shown that people with smaller apo(a) isoforms have approximately 2 -fold higher risk of CHD or ischemic stroke than those with larger isoforms [21]. Interestingly, they found that after adjustment for cholesterol and other CVD risk factors, the association was only slightly attenuated, strengthening the concept that $\mathrm{Lp}(\mathrm{a})$ is an independent risk factor for CHD. Likewise, European Prospective Investigation of Cancer cohort have observed that after adjustment for LDL-C, there is an association between Lp(a) levels and CVD [7]. Recently, Khera et al. analysed a subgroup of white participants of the JUPITOR study and showed that in statintreated patients with very low level of LDL-C, elevated $\mathrm{Lp}$ (a) levels represent a significant determinant of residual risk for CVD [22].

LPA gene polymorphism influences Lp(a) levels and the risk of myocardial infarction with some common variants of LPA gene associated with more than $50 \%$ risk of heart diseases $[1,2]$. Two gene association studies have suggested a causative relationships between elevated levels of $\mathrm{Lp}(\mathrm{a})$ and increased risk of CVD events. 
The 10 years Framingham cardiovascular risk score does not include $\mathrm{Lp}(\mathrm{a})$ levels. However, including it may improve risk assessment. To support this idea, several cohort of patients (both Caucasian and African-American patients) were used to develop 2013 American College of Cardiology/American Heart Association (ACC/AHA) cardiovascular risk calculator [20]. This model incorporated same parameters as the 2008 Framingham cardiovascular risk score except that it included only hard endpoints (both fatal and not fatal myocardial infarction and stroke). Thus, this calculator may be used in some populations; while it is not accurate in others (Rotterdam) [23, 24].

In addition, elevated levels of Lp(a) are associated with stroke, which is more common in men than women. Elevated $\mathrm{Lp}(\mathrm{a})$ in patients with essential hypertension seems to play a role in the development of target-organ damage. In one study, Sechi et al. have shown that regardless of blood pressure, Lp(a) levels were the best predictor of target-organ damage involving arterial wall, heart, and kidney [25].

$\mathrm{Lp}$ (a) may also play a role in plaque rupture and coronary thrombosis[23-26]. In patients with acute coronary syndrome, Lp(a) levels are predictive of risk of cardiac death.

\section{Screening}

Recommendations for $\mathrm{Lp}$ (a) screening are not standardized among atherosclerosis, lipid, and CV prevention societies. The 2013 ACC/AHA treatment guideline did not examine $\mathrm{Lp}(\mathrm{a})$ role and thus did not recommend $\mathrm{Lp}(\mathrm{a})$ screening [26]. However, both the National Lipid Association (NLA) and the European Atherosclerosis Society Consensus Panel recommended Lp(a) measurement for patients with familial hypercholesteremia, strong family history of CVD and/or elevated Lp(a), personal history of premature CVD, recurrent CVD despite statin treatment, inadequate response to statins, and $\geq 3 \% 10$-year risk of fatal CVD according to the European guideline, and $\geq 10 \% 10$-year risk of fatal or non-fatal CHD according to the US guidelines [12, 27]. The 2012 Canadian Cardiovascular Society recommend considering secondary testing, including $\mathrm{Lp}$ (a) measurement, in a moderate risk patients [28]. They emphasize that LDL-C reduction is the primary target in management of dyslipidemia.

\section{Cardiovascular risk in patients with elevated Lp(a)}

There is no definite clinical trial investigating effect of lowering $\mathrm{Lp}(\mathrm{a})$ on prevention of $\mathrm{CHD}$; thus, all recommendations for the treatment are speculative. Thus ACC/AHA guidelines does not identify Lp(a) as the primary target for lipid-lowering therapy [26]. The European Atherosclerosis Society Consensus Panel (EASCP) suggested that $\mathrm{Lp}$ (a) level below $500 \mathrm{mg} / \mathrm{L}$ are desirable [12]. The primary goal of treatment of elevated $\mathrm{Lp}(\mathrm{a})$ is to lower LDL-C to the patient's target LDL-C level based on patient's risk category. For reduction in CHD, EASCP considers assessing and possibly treating $\mathrm{Lp}(\mathrm{a})$ as a priority after lowering LDL-C. Studies suggest that risk of CVDassociated elevated Lp(a) levels is much higher in the presence of other CV risk factors including high LDL-C levels [29]. Several studies showed that lowering LDL-C in the presence of high $\mathrm{Lp}(\mathrm{a})$ resulted in a reduction in CVD events [30]. Thus, statins should be considered as a firstline therapy for the treatment of elevated LDL-C and $\mathrm{Lp}(\mathrm{a})$. Interestingly some studies recommend more aggressive treatment of LDL-C in the presence of high Lp(a) [2]; the effectiveness of this approach has not been fully studied. It should be noted that there is ongoing controversy about specific cholesterol targets. In patients with elevation of $\mathrm{Lp}(\mathrm{a})$ without an indication for LDL-C therapy, beneficial effect of statin for risk reduction is not clear.

Clinical studies investigating the effect of lowering Lp(a) and CHD risks seem to lack consistency in regards to patient selection, drugs used, and the method for Lp(a) measurement. LDL-C levels are frequently calculated using Friedwald equation which includes $\mathrm{Lp}(\mathrm{a})$. Using Dahlen equation, we and others have shown that in patients with high levels of $\mathrm{Lp}$ (a) this equation overestimates LDL-C $[31,32]$. In patients with extreme Lp(a) levels this overestimation is high (up to $40 \%$ ) [32]. Thus, in a patient with very high $\mathrm{Lp}$ (a) level, if LDL-C is driven lower pharmacologically, a larger proportion of calculated LDL-C is actually contributed by $\mathrm{Lp}(\mathrm{a})$. The recent IMPROVE-IT study proposed that lowering LDL-C level to $1.3 \mathrm{mmol} / \mathrm{L}$ is associated with lower repeated $\mathrm{CV}$ events compared to the higher levels [33]. However, it is important to estimate the true levels of LDL-C in this study and its relationship with CV events.

\section{Treatment}

Different classes of lipid-lowering medications have distinct effects on LDL and Lp(a). Statins and bile acid sequestrates reduce LDL-C, but lower Lp(a) only slightly. In patients with the familial hypercholesteremia statins decrease Lp(a) by 17-22 \% [34]. Some studies showed that statins may raise Lp (a) mass by 10-50\% [6]. Fibric acid derivatives do not decrease $\mathrm{Lp}$ (a) except for bezafibrate which lowered $\operatorname{Lp}(\mathrm{a})$ by $39 \%$ [35]. Bezafibrate is not approved for use in North America.

High dose of nicotinic acid (2-4 g/day) is the most effective agent that lowers $\mathrm{Lp}$ (a) by up to $40 \%[1,2]$. Percentage lowering appears to be greater at extreme Lp(a) levels. It also has other beneficial effects including reduction of LDL-C, apoB, small LDL-C, and triglycerides, and raises $\mathrm{HDL}-\mathrm{C}$. However, no study has correlated nicotinic acid-induced reduction in $\mathrm{Lp}$ (a) with CVD outcomes. In Post hoc analysis of the AIM-HIGH trial, 
Albers et al. have suggested that despite the fact that niacin induced favorable changes in lipid profile; it did not improved CV risk [36]. They suggested that in patients with elevated $\mathrm{Lp}(\mathrm{a})$ statins remain the basis of treatment with the target of reducing LDL-C below $1.8 \mathrm{mmol} / \mathrm{L}$. But this notion has not been studied in patients with extreme Lp(a) levels. The subsequent study, HSP-2-THRIVE study also failed to show a significant benefit in reducing major vascular events with nicotinic acid despite reduction in Lp(a) levels [37]. Also, the National Cholesterol Education Program Adult Treatment Panel III stated that the clinical utility of niacin is not fully established due to the fact that the frequency of extremely high $\operatorname{Lp}(\mathrm{a})$ level is low [20]. Interestingly, in a case report of a patient with normal lipid profile but extremely elevated $\mathrm{Lp}(\mathrm{a})$ who developed a non-ST elevation myocardial infarction, we have shown that treatment with a combination of nicotinic acid and statin may be beneficial in reducing further CHD events [38]. It is unclear if nicotinic acid has a role in reduction of CVD events. However, a recent meta-analysis suggests that nicotinic acid is useful for CV event reduction [39]. In patients with elevated Lp(a), EASCS recommends treatment with nicotinic acid $1-3 \mathrm{~g} / \mathrm{d}$ in high risk patients to achieve $\mathrm{Lp}(\mathrm{a})$ levels below $500 \mathrm{mg} / \mathrm{L}$ as a secondary goal after reduction of LDL-C [12].

There are also several recent pharmacologic developments pertinent to lowering $\mathrm{Lp}(\mathrm{a})$. One is mipomersen, an apoB antisense oligonucleotide that inhibits synthesis of apoB. This drug has been approved by FDA for lowering LDL-C, apoB, TC, and non-HDL-C in patients with homozygous familial hypercholesteremia $[1,2,40]$. A meta-analysis investigating the effect of this agent on $\mathrm{Lp}$ (a) levels have found a reduction of $26 \%$ in $\mathrm{Lp}(\mathrm{a})$ from baseline [1]. Due to its hepatotoxicity, this agent can only be prescribed by specially certified physicians.

Another development is human monoclonal antibody to Proprotein convertase subtilisin/kexin9 (PCSK9) $[1,2,40]$. PCSK9 is a protein which binds to LDLreceptor (LDL-R). This complex is subject to proteolytic degradation, thus preventing recycling of LDL-R to the cell surface and impairing the clearance of plasma LDL-C. The PROFICIO (Program to Reduce LDL and CV Outcomes Following Inhibition of PCSK9 In Different Populations) has shown that administration of Evolocumab, a PCSK9 inhibitor resulted in significant dose-dependent decrease in $\mathrm{Lp}$ (a) by up to $29.5 \%$ and LDL-C by $52 \%$ [41]. Alirocumab, another monoclonal antibody, showed similar results as evolocumab in terms of $\mathrm{Lp}(\mathrm{a})$ reduction $[1,40]$. In a meta-analysis of 20 randomized controlled trials, Li et al. demonstrated that treatment with PCSK9 inhibitor resulted in reduction in $\mathrm{Lp}(\mathrm{a})$ as well as other lipid parameters such as LDL-C, TC, triglycerides, and apoB. Even though PCSK9 inhibitors reduce Lp(a), their effect on CVD outcome remains unclear $[1,40]$. Also, it is unclear where PCSK9 inhibition fits into current therapeutic guidelines and whether this agent will be used to specifically lower $\mathrm{Lp}(\mathrm{a})$ in addition to the robust LDL-C reduction.

Lomitapide, and microsomal triglyceride transfer protein (MTP) inhibitor, approved by FDA as an adjunct to diet and lipid lowering therapy lowers LDL-C, TC, apoB, and non-HDL-C in patients with homozygous FH [42]. MTP transfers lipids to apoB in hepatocytes and enterocytes. MTP inhibition impair VLDL formation. In phase II clinical trial this agent has been shown to lower $\operatorname{Lp}(\mathrm{a})$ by $17 \%$ [40]. There is concern about its hepatotoxicity, thus, it should be prescribed by specifically certified physicians. The long-term effect of this agent on $L p(a)$ reduction needs to be determined.

Inhibitors of cholesterol ester transfer protein (CETP), a plasma protein that transfers cholesterol esters from HDL to apoB-containing particles raise HDL-C levels [40]. While the first trials of these inhibitors, torcetrapib and dalcetrapib were terminated due to side effects, newer agents anacetrapib and evacetrapib showed beneficial lipid effects without serious side effects. In the DEFINE trial, anacetrapib resulted in HDL-C elevation of $138 \%$ and lowering of LDL-C and Lp(a) by 40 and $36 \%$, respectively [43]. The effect of this agent on lowering CVD is under investigation.

Recently both animal and human studies have shown that specifically targeting $\mathrm{Lp}(\mathrm{a})$ with second generation antisense oligonucleotides lowers plasma level of $\mathrm{Lp}(\mathrm{a})$ by inhibiting apo(a) mRNA translation and thereby synthesis [44]. In a randomized, double-blind, placebocontrolled phase I study, Tsimikas et al. [45] have shown that treatment of volunteers with second generation antisense oligonucleotides that inhibits Lp(a) mRNA translation reduces $\mathrm{Lp}(\mathrm{a})$ levels and oxidized phospholipid associated with apo(B) levels, in a dose dependent manner, up to 89 and $93 \%$, respectively. They also showed this drug is safe and tolerable. It is a potent and selective in reducing $\mathrm{Lp}(\mathrm{a})$ levels, thus, it could be used as a potential therapeutic drug to reduce CVD events and progression.

Lipoprotein apheresis, an extracorporeal therapy, is the most effective way to lower $\operatorname{Lp}(a)[1,2,40]$. Several studies have shown its lowering effect on serum lipids and $\operatorname{Lp}(\mathrm{a})$ as well as its safety $[1,40]$. Currently, most lipid societies recommend apheresis mainly for patients with familial hypercholesteremia $[40,46]$. The German Committee of Physicians and Health Insurance Funds and England's HEART-UK recommend apheresis for patients with $\mathrm{Lp}(\mathrm{a})>600 \mathrm{mg} / \mathrm{L}$ with progressive $\mathrm{CHD}$ $[46,47]$. Both longitudinal cohort study and prospective observational study of patients with CHD and elevated $\mathrm{Lp}(\mathrm{a})$ levels showed that lipoprotein apheresis 
resulted in $L p(a)$ level reduction of more than $60 \%$ after each apheresis session as well as lowering major adverse coronary events rate per patient by almost $80 \%$ [40]. In a randomized controlled interventional study on patients receiving weekly lipoprotein apheresis, Safarova et al. demonstrated that lipoprotein apheresis resulted in $\mathrm{Lp}(\mathrm{a})$ level reduction by $73 \pm 12 \%$ [48]. Also, coronary angiography showed a reduction in median percent diameter stenosis by 2.0 compared to the group receiving only atorvastatin. Julius et al. demonstrated that lipoprotein apheresis resulted in reduction of $\mathrm{CV}$ events more significantly in patients with elevated $L p(a)$ levels compared to patients with elevated LDL-C levels [49]. Given that apheresis removes both $\mathrm{Lp}(\mathrm{a})$ and LDL-C, the therapeutic effects of apheresis seen in above studies is likely related to reduction in these particles. A major limitation of apheresis is that both $\mathrm{Lp}(\mathrm{a})$ and LDL-C levels, particularly $\mathrm{Lp}$ (a) levels, rebound to baseline levels within 2 weeks of treatment [40]. Other limitations include its cost and limited access.

\section{Future studies}

$\mathrm{Lp}(\mathrm{a})$ is considered as an risk factor for CVD. In order to be used for risk stratification and as a major cardiovascular risk factor, further studies should be conducted to show $\mathrm{Lp}(\mathrm{a})$ predictive power for CVD and beneficial effects of its lowering.

\section{Conclusions}

Epidemiologic and genetic studies provide evidence that $\mathrm{Lp}(\mathrm{a})$ is an independent, causal risk factor for CVD. Elevated $\mathrm{Lp}(\mathrm{a})$ levels promote atherosclerosis and thrombosis. Screening and treatment of selected patients are recommended. Diet, exercise, and lifestyle modification have no effect on Lp(a). Niacin and lipoprotein apheresis are the most effective ways currently available to lower $\mathrm{Lp}(\mathrm{a})$. Recent pharmaceutical developments show promising results on reduction in $L p(a)$ levels, but there is no study investigating their effect on CV events. Thus, large prospective randomized-controlled trials are needed to investigate relationship between lowering $\mathrm{Lp}(\mathrm{a})$ and reduction in CVD.

\section{Competing interest}

The authors declare that they have no competing interests.

\section{Authors' contribution}

RS wrote the first draft of the manuscript and JF edited it. Both authors read and approved the final manuscript.

\section{Acknowledgement}

N/A

Received: 29 July 2015 Accepted: 10 March 2016

Published online: 31 March 2016

\section{References}

1. Kassner U, Schlabs T, Rosada A. Lipoprotein(a)-An independent causal risk factor for cardiovascular disease and current therapeutic options. Atheroscler Suppl. 2015:18:263-7.

2. Jacobson TA. Lipoprotein(a). Cardiovascular Disease, and Contemporary Management. Mayo Clin Proc. 2013:88(11):1294-311.

3. Nielsen LB, Grønholdt ML, Schroeder TV, et al. In vivo transfer of lipoprotein(a) into human atherosclerotic carotid arterial intima. Arterioscler Thromb Vasc Biol. 1997;17(5):905-11.

4. Erqou S, Kaptoge S, Perry PL, et al. Emerging Risk Factors Collaboration, et al. Lipoprotein(a) concentration and the risk of coronary heart disease, stroke, and nonvascular mortality. JAMA. 2009;302(4):412-23.

5. Boffa MB, Marcovina SM, Koschinsky ML. Lipoprotein(a) as a risk factor for atherosclerosis and thrombosis: mechanistic insights from animal models. Clin Biochem. 2004;37(5):333-43.

6. Yeang $C$, Witztum JL, Tsimikas S. 'LDL-C' $=L D L-C+L p(a)-C$ : implications of achieved ultra-low LDL-C levels in the proprotein convertase subtilisin/kexin type 9 era of potent LDL-C lowering. Curr Opin Lipidol. 2015;26(3):169-78.

7. Dubé JB, Boffa MB, Hegele RA, et al. Lipoprotein(a): more interesting than ever after 50 years. Curr Opin Lipidol. 2012;23(2):133-40.

8. Ohira T, Schreiner PJ, Morrisett JD, et al. Lipoprotein(a) and incident ischemic stroke: the Atherosclerosis Risk in Communities (ARIC) study. Stroke. 2006;37(6):1407-12.

9. Matthews KA, Sowers MF, Derby CA, et al. Ethnic differences in cardiovascular risk factor burden among middle-aged women: Study of Women's Health Across the Nation (SWAN). Am Heart J. 2005;149(6):1066-73.

10. Lippi G, Guidi G. Lipoprotein(a): an emerging cardiovascular risk factor. Crit Rev Clin Lab Sci. 2003:40:1-42.

11. Marcovina SM, Albers JJ, Scanu AM, et al. Use of a reference material proposed by the International Federation of Clinical Chemistry and Laboratory Medicine to evaluate analytical methods for the determination of plasma lipoprotein(a). Clin Chem. 2000;46(12):1956-67.

12. Nordestgaard BG, Chapman MJ, Ray K, et al. Lipoprotein(a) as a cardiovascular risk factor: current status. Eur Heart J. 2010;31(23):2844-53.

13. Marcovina SM, Koschinsky ML, Albers JJ, et al. Report of the National Heart, Lung, and Blood Institute Workshop on Lipoprotein(a) and Cardiovascular Disease: recent advances and future directions. Clin Chem. 2003:49(11):1785-96.

14. von Eckardstein $A$, Schulte $H$, Cullen $P$, et al. Lipoprotein(a) further increases the risk of coronary events in men with high global cardiovascular risk. J Am Coll Cardiol. 2001;37(2):434-9.

15. Rouy D, Grailhe P, Nigon F, et al. Lipoprotein(a) impairs generation of plasmin by fibrin-bound tissue-type plasminogen activator. In vitro studies in a plasma milieu. Arterioscler Thromb. 1991;11:629-38.

16. Kamstrup PR, Tybjærg-Hansen A, Nordestgaard BG. Extreme lipoprotein(a) levels and improved cardiovascular risk prediction. J Am Coll Cardiol. 2013; 61(11):1146-56.

17. Kamstrup PR, Benn M, Tybjærg-Hansen A, et al. Extreme lipoprotein(a) levels and risk of myocardial infarction in the general population: the Copenhagen City Heart Study. Circulation. 2008:117:176-84.

18. Willeit $P$, Kiechl S, Kronenberg F, et al. Discrimination and net reclassification of cardiovascular risk with lipoprotein(a): prospective 15-year outcomes in the Bruneck Study. J Am Coll Cardiol. 2014;64(9):851-60.

19. Genest J. Lipoprotein disorders and cardiovascular risk. J Inherit Metab Dis. 2003;26(2-3):267-87

20. National Cholesterol Education Program (NCEP) Expert Panel on Detection, Evaluation, and Treatment of High Blood Cholesterol in Adults (Adult Treatment Panel III). Third Report of the National Cholesterol Education Program (NCEP) Expert Panel on Detection, Evaluation, and Treatment of High Blood Cholesterol in Adults (Adult Treatment Panel III) final report. Circulation. 2002;106(25):3143-421.

21. Emerging Risk Factors Collaboration, Erqou S, Kaptoge S, Perry PL, et al. Lipoprotein(a) concentration and the risk of coronary heart disease, stroke, and nonvascular mortality. JAMA. 2009;302(4):412-23.

22. Khera AV, Everett BM, Caulfield MP, et al. Lipoprotein(a) concentrations, rosuvastatin therapy, and residual vascular risk: an analysis from the JUPITER Trial (Justification for the Use of Statins in Prevention: an Intervention Trial Evaluating Rosuvastatin). Circulation. 2014;129(6):635-42.

23. Kavousi M, Leening MJ, Nanchen D, et al. Comparison of application of the ACC/AHA guidelines, Adult Treatment Panel III guidelines, and European 
Society of Cardiology guidelines for cardiovascular disease prevention in a European cohort. JAMA. 2014;311:1416.

24. Karmali KN, Goff Jr DC, Ning H, et al. A systematic examination of the 2013 ACC/AHA pooled cohort risk assessment tool for atherosclerotic cardiovascular disease. J Am Coll Cardiol. 2014;64:959.

25. Sechi LA, Kronenberg F, De Carli S, et al. Association of serum lipoprotein(a) levels and apolipoprotein(a) size polymorphism with target-organ damage in arterial hypertension. JAMA. 1997;277:1689.

26. Goff Jr DC, Lloyd-Jones DM, Bennett G, et al. 2013 ACC/AHA guideline on the assessment of cardiovascular risk: a report of the American College of Cardiology/American Heart Association Task Force on Practice Guidelines. Circulation. 2014;129:549.

27. Davidson MH, Ballantyne $C M$, Jacobson $T A$, et al. Clinical utility of inflammatory markers and advanced lipoprotein testing: advice from an expert panel of lipid specialists. J Clin Lipidol. 2011;5(5):338-67.

28. Anderson TJ, Gregoire J, Hegele RA, et al. 2012 update of the Canadian Cardiovascular Society guidelines for the diagnosis and treatment of dyslipidemia for the prevention of cardiovascular disease in the adult. Can J Cardiol. 2013;29(2):151-67.

29. LuC G, Bard JM, Arveiler D, et al. Lipoprotein (a) as a predictor of coronary heart disease: the PRIME Study. Atherosclerosis. 2002;163(2):377-84.

30. Maher VM, Brown BG, Marcovina SM, et al. Effects of lowering elevated LDL cholesterol on the cardiovascular risk of lipoprotein(a). JAMA. 1995;274(22):1771-4.

31. Saeedi R, Li M, Allard M, Frohlich J. Marked effects of extreme levels of lipoprotein(a) on estimation of low-density lipoprotein cholesterol. Clin Biochem. 2014;47(12):1098-9.

32. Li KM, Wilcken DE, Dudman NP. Effect of serum lipoprotein(a) on estimation of low-density lipoprotein cholesterol by the Friedewald formula. Clin Chem. 1994;40(4):571-3.

33. Cannon CP, Blazing MA, Giugliano RP, et al. Ezetimibe Added to Statin Therapy after Acute Coronary Syndromes. N Engl J Med. 2015;18;372(25):2387-97.

34. Van van Wissen S, Smilde TJ, Trip MD, et al. Long term statin treatment reduces lipoprotein(a) concentrations in heterozygous familial hypercholesterolaemia. Heart. 2003;89:893-6.

35. Børresen AL, Berg K, Dahlén G, et al. The effect of Gemfibrozil on human serum apolipoproteins and on serum reserve cholesterol binding capacity (SRCBC). Artery. 1981;9:77.

36. Albers JJ, Slee A, O'Brien KD, et al. Relationship of apolipoproteins A-1 and $B$, and lipoprotein(a) to cardiovascular outcomes: the AIM-HIGH trial (Atherothrombosis Intervention in Metabolic Syndrome with Low HDL/High Triglyceride and Impact on Global Health Outcomes). J Am Coll Cardiol. 2013;62(17):1575-9.

37. Hps Thrive Collaborative Group. HPS2-THRIVE randomized placebocontrolled trial in 25673 high-risk patients of ER niacin/laropiprant: trial design, pre-specified muscle and liver outcomes, and reasons for stopping study treatment. Eur Heart J. 2013;34(17):1279e91.

38. Li M, Saeedi R, Rabkin SW, Frohlich J. Dramatic lowering of very high Lp(a) in response to niacin. J Clin Lipidol. 2014;8(4):448-50.

39. Lavigne PM, Karas RH. The current state of niacin in cardiovascular disease prevention: a systematic review and meta-regression. J Am Coll Cardiol. 2013;61(4):440-6.

40. Man LC, Kelly E, Duffy D. Targeting lipoprotein (a): an evolving therapeutic landscape. Curr Atheroscler Rep. 2015;17(5):502.

41. Koren MJ, Giugliano RP, Raal FJ, et al. Efficacy and safety of longer-term administration of evolocumab (AMG 145) in patients with hypercholesterolemia: 52-week results from the Open-Label Study of Long-Term Evaluation against LDL-C (OSLER) randomized trial. Circulation. 2014;129(2):234e43.

42. Juxtapid (lomitapide) capsules [package insert]. Cambridge, MA; Aegerion Pharmaceuticals. Revised August, 2014.

43. Gotto Jr AM, Kher U, Chatterjee MS, et al. Lipids, safety parameters, and drug concentrations after an additional 2 years of treatment with anacetrapib in the DEFINE study. J Cardiovasc Pharmacol Ther. 2014;19(6):543-9.

44. Graham MJ, Viney N, Crooke R, et al. Antisense Inhibition of Apolipoprotein(a) to Lower Plasma Lipoprotein(a) Levels in Humans. J Lipid Res. 2015 Nov 4. pii: jlr.R052258. [Epub ahead of print]

45. Tsimikas S, Viney NJ, Hughes SG, et al. Antisense therapy targeting apolipoprotein(a): a randomised, double-blind, placebo-controlled phase 1 study. Lancet. 2015;386(10002):1472-83.
46. Thompson GR. Recommendations for the use of $L D L$ apheresis. Atherosclerosis. 2008;198(2):247-55.

47. Leebmann J, Roeseler E, Julius U, et al. Lipoprotein apheresis in patients with maximally tolerated lipid-lowering therapy, lipoprotein(a)hyperlipoproteinemia, and progressive cardiovascular disease: prospective observational multicenter study. Circulation. 2013;128(24):2567-76.

48. Safarova MS, Ezhov MV, Afanasieva Ol, et al. Effect of specific lipoprotein(a) apheresis on coronary atherosclerosis regression assessed by quantitative coronary angiography. Atheroscler Suppl. 2013;14(1):93e9.

49. von Dryander M, Fischer S, Passauer J, Muller G, et al. Differences in the atherogenic risk of patients treated by lipoprotein apheresis according to their lipid pattern. Atheroscler Suppl. 2013;14(1):39e44.

\section{Submit your next manuscript to BioMed Central and we will help you at every step:}

- We accept pre-submission inquiries

- Our selector tool helps you to find the most relevant journal

- We provide round the clock customer support

- Convenient online submission

- Thorough peer review

- Inclusion in PubMed and all major indexing services

- Maximum visibility for your research

Submit your manuscript at www.biomedcentral.com/submit
C Biomed Central 